\title{
A POLítICA DE INTERNACIONALIZAÇÃo dA EDUCAÇÃo SUPERIOR NO PLANO NACIONAL de PóS-GRAdUAÇÃo (2011-2020)
}

\begin{tabular}{c}
\hline THE INTERNATIONALIZATION OF HIGHER EDUCATION \\
POLICY NATIONAL GRADUATE (2011-2020) \\
\hline LA POLÍTICA DE INTERNACIONALIZAÇÃO DE LA EDUCACIÓN SUPERIOR \\
EN EL PLAN NACIONAL DE POSGRADO (2011-2020)
\end{tabular}

João dos Reis Silva Júnior ${ }^{1}$ Fabíola Bouth Grello Kato ${ }^{2}$

\begin{abstract}
RESUMO
O objetivo do texto consiste em mostrar o processo de internacionalização em curso no país desde a adesão do país à predominância financeira durante o governo de FHC, que teve continuidade nos governos Lula e Dilma, tendo como base o Plano Nacional de Pós-graduação (2011-2020). Para além de mostrar o processo, busca indagar as razões dele encontrando alguma resposta na mundialização da economia e na necessidade da produção de uma episteme econômica exigida pela mundialização da economia. As consequências para o trabalho do professor e a respectiva perda de seus direitos sociais é aqui o corolário do processo.
\end{abstract}

PALAVRAS-CHAVE: Internacionalização da educação superior. Predominância financeira. Pós-graduação.

\section{ABSTRACT}

The purpose of the paper is to show the ongoing internationalization process in the country since the country's accession to the financial dominance during the government of Fernando Henrique Cardoso, which continued in the Lula and Dilma governments, based on the National Plan for Graduate (2011 -2020). In addition to displaying the process, search ask his reasons finding an answer in the globalization of the economy and the need for the production of an economic episteme required by the globalization of the economy. The consequences for the work of teachers and their loss of their social rights here is the corollary of the process.

KEYWORDS: Internationalization of higher education. Financial dominance. Postgraduate studies.

\section{RESUMEN}

El objetivo del texto consiste en mostrar el proceso de internacionalización en curso en el país desde su adhesión a la predominancia financiera durante el gobierno de FHC, que tuvo continuidad en los gobiernos Lula y Dilma, teniendo como base el Plan Nacional de Posgrado (2011-2020). Además de mostrar el proceso, busca indagar sus razones, encontrando alguna respuesta en la mundialización de la economía y en la necessidade da produção de uma episteme econômica exigida pela mundialização da economia. As consequências para o trabalho do professor e a respectiva perda de seus direitos sociais é aqui o corolário do processo.

PALABRAS-CLAVE: Internacionalização da educação superior. Predominância financeira. Pós-graduação.

\footnotetext{
${ }^{1}$ Mestre em Administração e Doutor em Educação pela PUC-SP. Pós-Doutorado em Sociologia Política pela UNICAMP. Professor do Programa de Pós-graduação em Educação da UFSCar. Pesquisador do CNPq. ORCID: http://orcid.org/0000-0003-2667-0371.

E-mail: jr@ufscar.br.

${ }^{2}$ Mestra e Doutorae m Educação pela UFSCar. Professora Adjunta do Programa de Pós-graduação em Educação/PPGED/UFPA. E-mail: fabiola_kato@ hotmail.com
}

Submetido em: 11/11/2015 - Aceito em: 09/02/2016

\begin{tabular}{l|l|l|l|l|l|l}
\hline (C) Rev. Inter. Educ. Sup. & Campinas, SP & v.2 & n.1 & p.138-151 & jan./abr. 2016 & ISSN 2446-9424
\end{tabular}




\section{Introdução}

Em 11 de janeiro de 2016, a presidenta Dilma Rousseff sancionou diante de Ministros do Estado (Ministro Celso Pansera, da Ciência, Tecnologia e inovação; o ministro Aldo Rebelo, da Defesa, ex-ministro da Ciência, Tecnologia e Inovação; o ministro Aloizio Mercadante da Educação; o ministro Marcelo Castro, da Saúde; o ministro Armando Monteiro, do Desenvolvimento, Indústria e Comércio Exterior), dos presidentes de nossas principais associações científicas nacionais, Hernan Chaimovich, presidente do Conselho Nacional de Desenvolvimento Científico e Tecnológico (CNPq); Jacob Palis, presidente da Academia Brasileira de Ciência; a presidente da Associação Brasileira para o Progresso da Ciência (SBPC), Helena Nader, e ainda aos professores, pesquisadores de instituições de ensino e pesquisa e o empresariado brasileiro a Lei n. 13.243/2016, mais conhecida como "novo marco legal da Ciência, Tecnologia e Inovação".

A sanção desta Lei, de acordo com a presidente, auxiliará no cumprimento da nova agenda nacional que facilitará a relação de cooperação entre a comunidade científica (Universidades e Institutos públicos), o governo e o setor empresarial.

Em seu discurso, Dilma reconhece tal marco regulatório como parte de um projeto de Estado que conduzirá o Brasil a um novo ciclo de desenvolvimento econômico e social, onde o chamado novo Código Nacional de Ciência, Tecnologia e Inovação fomentará as bases legais e institucionais para a geração do conhecimento necessário para a atual etapa de desenvolvimento econômico do país.

(...) A primeira é que o Brasil possui uma extraordinária capacidade, um imenso potencial de produzir conhecimento e que, infelizmente, ainda não tem se traduzido em idêntica capacidade de transformar esses conhecimentos em inovação produtiva integralmente. A segunda é que em um ambiente regulatório e institucional mais favorável à cooperação entre universidades, laboratórios de pesquisa, governos, empresas, enfim, universidades, empresas e estados, nesse ambiente mais favorável transformaremos, certamente, mais ciência básica em inovação e transformaremos inovação em competitividade gerando um novo ciclo de desenvolvimento econômico no nosso País (DILMA, 2016).

Entre as ações destacadas que propiciarão as condições institucionais para a transformação de nossa produção científica em produtos e processos inovadores para o setor produtivo brasileiro, Dilma ponderou a necessidade de promoção dessa 'reforma' na legislação que regula a relação entre agentes públicos e privados que atuam na área científica. Para a presidente, a nova lei traz mais agilidade, maior flexibilidade e reduz a burocracia no setor, inaugurando um ‘novo ciclo de desenvolvimento' (DILMA, 2016).

O novo marco legal propõe mudanças significativas no ambiente regulatório de cooperação entre agentes públicos e privados que alteram, inclusive, as relações de trabalho no interior das Instituições Federais de Ensino Superior (IFES): cria exceções que dispensa licitações para aquisição ou contratação de produtos para pesquisa; dispõe sobre a contratação

\begin{tabular}{l|l|l|l|l|l|l} 
(C) Rev. Inter. Educ. Sup. & Campinas, SP & v.2 & n.1 & p.138-151 & jan./abr. 2016 & ISSN 2446-9424
\end{tabular}


de pesquisadores e técnicos para projetos por tempo determinado e dispõe sobre a estruturação do Plano de Carreiras e Cargos de Magistério Federal no qual amplia o número de horas que pesquisadores da rede pública em regime de dedicação exclusiva podem se dedicar a atividades no setor privado, de 120 para 416 horas anuais, ou 8 horas semanais.

Isso vai possibilitar a justa remuneração das universidades públicas e dos centros de pesquisa, propiciando mais recursos para investimento e para novos avanços na qualidade da educação e da produção de conhecimento. Permitirá, portanto, transformar a inovação bem sucedida em patrimônio de toda a sociedade brasileira. Temos, portanto, muitos motivos para celebrar o novo Código Nacional de Ciência, Tecnologia e Inovação. Abrimos sem dúvida uma nova etapa na cooperação entre universidades, institutos de pesquisa, Estado e empresas, cujos resultados serão mais oportunidades para nossa população e mais competitividade para o nosso País (DILMA, 2016).

O chamado novo Código Nacional de Ciência, Tecnologia e Inovação ao que parece, traduz-se na atualização de um projeto nacional que vem a conta-gotas institucionalizando, desde a década de 1990, o processo de mercantilização da educação superior. Tal projeto nacional pode ser recentemente avaliado com a publicação do atual Plano Nacional de Pósgraduação-PNPG (2011-2020), e das ações dali derivadas, que traduz de modo claro o papel que a ciência cumpre na atual etapa de desenvolvimento econômico do país.

Quando retomamos a leitura do mais recente manifesto político orientador das práticas de promoção de Ciência, Tecnologia e Inovação do país, ou seja, o atual PNPG (2011-2020), relembramos que uma das principais metas expostas naquele documento para a próxima década seria as mudanças nas condições institucionais para a produção de conhecimento. A leitura do novo código nacional de C,T\&I vem atender tal demanda, colaborando para flexibilização das regulações até então impostas ao setor público.

\begin{abstract}
Junto com o financiamento, o marco regulatório do sistema deverá ser continuamente aprimorado e novos procedimentos incorporados, envolvendo a sinergia de vários ministérios e órgãos federais. Duas são as direções: 1-a busca de uma maior flexibilização e implicação de procedimentos, como na importação de insumos e instrumentos [...]; 2 - a busca de melhor equacionamento $\mathrm{e}$ regulamentação da relação entre o público e o privado, permitindo o estabelecimento de parcerias e agilização das ações, como o pagamento de consultorias, nacionais e internacionais, sem prejuízo da exigência de acompanhamento das atividades pelos órgãos de controle. (BRASIL, 2010, p.23)
\end{abstract}

O queremos demonstrar com a publicação da Lei n. 13.243/2016 é que há um projeto nacional de Ciência, Tecnologia e Inovação (C,T\&I) em curso no país, sobretudo, a partir da década 1990, quando o Brasil inicia um processo de atualização dos fundamentos da sua economia, aderindo ao capitalismo de predominância financeira ${ }^{3}$ e iniciando no país uma

\footnotetext{
${ }^{3}$ Esse novo processo de reorganização econômica e política da atual etapa do capitalismo é conhecidos por "mundialização do capital", expressão cunhada por Chesnais (1996) para designar um movimento em que uma empresa forte num ramo industrial, descentraliza-se em diversas unidades por todo o mundo, em diversos países ou regiões, na busca de maiores vantagens produtivas: menores custos e maiores vantagens quanto a força de trabalho, matéria prima, leis trabalhistas, universidades à serviço das empresas. Aqui, para Silva Jr (2012)

\begin{tabular}{l|l|l|l|l|l|l} 
(C) Rev. Inter. Educ. Sup. & Campinas, SP & v.2 & n.1 & p.138-151 & jan./abr. 2016 & ISSN 2446-9424
\end{tabular}
} 
série de ajustes estruturais, sobretudo jurídicos, com sua máxima expressão no Plano Diretor de reforma do Aparelho do Estado, publicado em 1995, cujo objetivo central seria de transformar o país numa econômica juridicamente atrativa para novas formas de valorização de capital baseado, sobretudo, na desregulamentação trabalhista, gestão monetária da economia e na atração de Investimento Externo Direto (IED).

O objetivo deste texto, portanto, é retomar o debate iniciado em 2012 quando os autores publicaram o artigo "PNPG (2011-2020): certificação em massa, internacionalização e mercantilização do conhecimento", que naquela ocasião propuseram-se a analisar as diretrizes do Plano Nacional de Pós-graduação (2011-2020) e as mudanças estruturais ali propostas com vistas a reorganizar a racionalidade científica brasileira com base na hipótese defendida em trabalhos recentes de que a universidade é a espinha dorsal do desenvolvimento capitalista atual e que tornou-se linha de continuidade do Estado, um instrumento de produção direta para o capital financeiro (SILVA JÚNIOR; KATO, 2012).

\section{PNPG (2011-2020): a atual proposta de internacionalização da pós- graduação}

Oficialmente o Plano Nacional de Pós-Graduação (PNPG) 2011-2020 tem como objetivo definir novas diretrizes, estratégias e metas para dar continuidade e avançar nas propostas para política de Pós-graduação e pesquisa no Brasil. A leitura atenta deste documento nos indica que um dos eixos centrais para a condução e desenvolvimento do Sistema Nacional de Pós-graduação (SNPG) é a política de internacionalização e cooperação internacional.

Quando apresentado os antecedentes do PNPG, notamos que há uma indução histórica, de base econômica, expressa nos planos anteriores que colaboram com nossa hipótese já apresentada em trabalho recentes ${ }^{4}$, de que há uma relação direta entre a condução política do nosso recém Sistema Nacional de Pós-graduação e o nosso modelo de desenvolvimento econômico que funcionaliza o papel da universidade e do conhecimento ali produzido.

Quando da aprovação do primeiro e segundo Plano Nacional de Pós-Graduação (I PNPG (1975-1979) e II PNPG (1982-1985)), notamos que este planejamento cumpriu com as atividades de formação de especialistas docentes, pesquisadores e quadros técnicos para atuar junto ao setor universitário, ao setor público e industrial (BRASIL, 2010). Dito de outro modo, a indução deste planejamento em nível de pós-graduação visou dar sustentabilidade para a formação de pessoal necessária para o desenvolvimento acadêmico, burocrático e produtivo do país.

residiria a diferença entre internacionalização e a mundialização da economia, uma vez que nesta nova etapa o capital produtivo também se internacionaliza na forma de Investimento Externo Direto (IED).

${ }^{4}$ KATO (2013); SILVA JR; KATO (2012) SILVA JR; KATO; RODRIGUES (2013; 2015).

\begin{tabular}{l|l|l|l|l|l|l} 
(C) Rev. Inter. Educ. Sup. & Campinas, SP & v.2 & n.1 & p.138-151 & jan./abr. 2016 & ISSN 2446-9424
\end{tabular} 
Na aprovação do III PNPG (1986-1989) e IV PNPG, este último, na verdade, nunca se efetivou de fato por não ter sido publicado oficialmente, notamos a subordinação direta das atividades de pós-graduação ao desenvolvimento econômico do país, mediante a integração das atividades de Ciência e Tecnologia (C\&T) expressas pela criação, em 1985, do Ministério da Ciência e Tecnologia (MCT) com vistas a contribuir para a inserção do Brasil na nova dinâmica econômica e social, que exigiria, a partir de então, muito mais que fomento a formação de recursos humanos qualificados (KATO, 2013).

A análise do atual Plano Nacional de Pós-Graduação (2011-2020), seguindo essa linha de continuidade histórica, também vem buscando o aperfeiçoamento da sinergia Ciência, Tecnologia e Inovação para o desenvolvimento econômico do país. A leitura do referido plano indicou que ele apresenta diretrizes para a adoção de uma política de Estado que objetiva integrar um plano nacional de desenvolvimento econômico e social a um plano nacional de pós-graduação no qual a universidade e sua estrutura acadêmico-científica, técnica e pedagógica contribui para a inserção do país num sistema econômico mundial e competitivo por mercados (SILVA JÚNIOR; KATO, 2012).

O país entrou no século XXI como uma nova potência emergente, com a perspectiva de tornar-se a quinta economia do planeta no decênio 2011-2020, tratase de um fato extraordinário, revelando que o país vem passando e deverá passar mais ainda por mudanças profundas em segmentos importantes da economia, com reflexos na geopolítica mundial e impactos em diferentes setores da sociedade, inclusive no sistema educacional, aí incluído o ensino superior. (BRASIL, 2010, p.16)

Desse modo, cumprindo as exigências do presente artigo, nos deteremos a analisar tal objetivo com base nesse planejamento do SNPG por meio da Política de internacionalização da C\&T brasileira para o avanço econômico do país no próximo decênio. Os dados apresentados no atual PNPG demonstram o avanço histórico da produtividade científica brasileira e da maturidade acadêmico-científica de nossa recente estrutura pós-graduada.

A internacionalização, podendo ser analisada com base em trocas econômicas, políticas e culturais entre países, portanto, é definida nesse Plano por meio de três eixos centrais: $\mathrm{O}$ envio de estudantes ao exterior para a realização do nível de doutoramento com vistas a dinamizar o sistema de captação de conhecimento novo; O estímulo à atração de mais alunos e pesquisadores visitantes e estrangeiros e o aumento do número de publicação com/em instituições estrangeiras.

$\mathrm{Na}$ apresentação do Plano, avanço da ciência brasileira é avaliado, em termos qualitativos, pela análise histórica da produção científica (1981-2009) tendo como fundamento os parâmetros de bases de classificação de indicadores científicos internacionais como ISI e SCOPUS que avaliam a produção científica em relação aos países, ao número de citações desses artigos, ao seu fator de impacto e às áreas do conhecimento. De acordo com as tabelas apresentadas o Brasil tem evoluído na internacionalização de sua pesquisa, e que

\begin{tabular}{l|l|l|l|l|l|l} 
(C) Rev. Inter. Educ. Sup. & Campinas, SP & v.2 & n.1 & p.138-151 & jan./abr. 2016 & ISSN 2446-9424 \\
\hline
\end{tabular}


cumpririam ao atual planejamento da Pós-graduação, mecanismos de incentivo para a promoção e evolução desses indicadores.

Não podemos deixar de destacar que grande parte desses considerados avanços científicos foram/são induzidos por políticas setoriais, exigidos por uma nova etapa brasileira de desenvolvimento econômico, executadas por duas importantes agências brasileiras: Coordenação de Aperfeiçoamento de Pessoal de Nível Superior- CAPES e Conselho Nacional de Desenvolvimento Científico e Tecnológico-CNPq.

\begin{abstract}
Duas questões merecem destaque: primeiro, o papel centralizador e arbitrário da CAPES na figura do Estado, que por meio de critérios de excelência cria um ranking, impondo a estas instituições um selo de qualidade [...] e em segundo lugar a forte indução de pesquisas via financiamento e processos avaliativos na criação de uma nova sociabilidade científica brasileira caracterizada de forma predominante pela: aceitação, pelo não-debate, pelo total descompromisso com pesquisas livres, por novos formatos e modelos de formação pós-graduada que diminui seus tempos de formação e fomenta mudança nos formatos dos programas com disciplina que primam muito mais pela formação técnica em detrimento da epistemologia. Sem grandes opções aos programas que se sentem compelidos a assumir tais características sob o risco de perda de credenciais, bolsas, verbas para pesquisas dentre outros mecanismos (SILVA JÚNIOR; KATO; FERREIRA, 2015, p.216).
\end{abstract}

No caso da agência $\mathrm{CNPq}^{5}$, a partir dos anos 2000 passou-se a incorporar um novo modelo de financiamento público de pesquisa expresso na publicação dos primeiros editais de apoio à pesquisa científica e tecnológica tendo como suporte um novo aparato jurídico-legal (Lei de Inovação Tecnológica (Lei n. 10.973/2004), Lei do Bem (Lei n. 11.196/2005) no qual tal desenho da política de financiamento passa a se orientar pela Política Industrial, Tecnológica e de Comércio Exterior (PITCE) que baseia-se: no foco à inovação, incentivo na formação de um pesquisador-criador, ênfase nas pesquisas de natureza aplicada em detrimento das pesquisas de natureza acadêmica, forte subvenção pública orientada para o crescimento econômico, visando posicionar o Brasil em Plataforma de valorização financeira (PAULANI, 2008).

Esse novo escopo do Sistema Nacional de Pós-Graduação (SNPG) abrangeria, de acordo com o documento, novas diretrizes para o sistema, caracterizadas pela diferenciação institucional entre os programas de pós-graduação strictu sensu, com recomendações para diminuição da entronização do modelo de universidade Humlboditiana, cabendo à CAPES o papel de incentivar e conduzir, a despeito do pretenso desenvolvimento econômico e social do país, a formação pós-graduada voltados para atividades extra-acadêmicas com destaque para o incentivo a criação de mestrados profissionais ainda incipientes no atual sistema.

\footnotetext{
5 Para compreender melhor o papel dessa agência e o novo paradigma de financiamento de pesquisas implementado a partir nos anos 2000 consultar a tese: KATO, Fabíola. A nova política de financiamento de pesquisas: reforma no Estado e no novo papel do CNPq. 2013.179f. Tese (Doutorado em Educação)-UFSCar, São Carlos.
} 
No topo do sistema estão as universidades humboldtianas, conhecidas por patrocinarem a união indissolúvel do ensino e da pesquisa, com a pós-graduação à frente, servindo de modelo ou farol para o sistema. Porém, no primeiro mundo e no Brasil, elas são a minoria, apresentando toda sorte de distorções: trata-se de um conceito ou de um ideal, a exigir ajustes ao ser trazido para os dias de hoje e aplicado à realidade das instituições. Não obstante, elas existem e deverão ser cobradas nas avaliações por sua inserção internacional ou pela capacidade de oferecer cursos de padrão internacional. Ao lado das universidades públicas humboldtianas e de uma ou outra comunitária que integra aquele prestigioso rol, há as públicas não-humboldtianas e as privadas, distinguidas entre as comunitárias e as não-comunitárias, com menos vocação acadêmica e maior proximidade com o mercado e, por vezes, com o setor produtivo. Este conjunto de natureza diferente e complementar deverá responder por demandas e necessidades diferentes: num extremo, a necessidade de formar professores e pesquisadores voltados para o sistema de ensino e de pesquisa; noutro extremo, a necessidade de formar quadros e técnicos altamente especializados para os setores públicos e privado (BRASIL, 2010, p.128).

Dentre as principais recomendações indicadas no âmbito do atual PNPG para o incentivo a internacionalização e cooperação internacional estão: envio de mais estudantes ao exterior para fazer doutorado, em vista da dinamização do sistema e da captação de novos recursos; estímulo à atração de mais alunos e pesquisadores visitantes e estrangeiros; aumento do número de publicações com instituições estrangeiras (BRASIL, 2010, p.303).

A condução política dessas recomendações encontra-se em pleno processo de desenvolvimento. Tal afirmativa se confirma, por exemplo, pelo fato de que na aprovação do atual Plano Nacional de Educação ${ }^{6}$-PNE (2014-2024) pela primeira vez contemplam-se diretrizes para a pós-graduação. Tais diretrizes estão descritas na meta 12 e 14 e apontam estratégias específicas no que diz respeito à Política de internacionalização.

12.12. Consolidar e ampliar programas e ações de incentivo à mobilidade estudantil e docente em cursos de graduação e pós-graduação, em âmbito nacional e internacional, tendo em vista o enriquecimento da formação de nível superior; 14.9. Consolidar programas, projetos e ações que objetivem a internacionalização da pesquisa e da pós-graduação brasileiras, incentivando a atuação em rede e o fortalecimento de grupos de pesquisa; 14.10. Promover o intercâmbio científico e tecnológico, nacional e internacional, entre as instituições de ensino, pesquisa e extensão; 14.11. Ampliar o investimento em pesquisas com foco em desenvolvimento e estímulo à inovação, bem como incrementar a formação de recursos humanos para a inovação, de modo a buscar o aumento da competitividade das empresas de base tecnológica; 14.13. Aumentar qualitativa e quantitativamente o desempenho científico e tecnológico do país e a competitividade internacional da pesquisa brasileira, ampliando a cooperação científica com empresas, instituições

\footnotetext{
${ }^{6}$ Lei n. 13.005 de 25 de junho de 2014. Aproveito a nota que trata da lei para fazer uma ressalva. De fato, este é um processo que tem sua origem no governo FHC e a adesão do Brasil ao Regime de Predominância Financeira. Encontra eco e se amplia nos governos de Lula e segue no primeiro governo de Dilma até a crise que se instala em 2014 e que no momento que redigimos este texto as evidências mostram que os investimentos no MCTI eram de $\mathrm{R} \$ 8,4$ bilhões em 2013 e caindo para $\mathrm{R} \$ 3,3$ bilhões em 2016. As consequências deste corte orçamentário para as bolsas no exterior para doutorado foram sensíveis, em 2014 eram 7.800 novas bolsas concedidas, em 2015 apenas 68 e a previsão para 2016 é zero. Destaca-se as bolsas vigentes que se encontram em processo de abrupto descenso. Disponível em http://ciencia.estadao.com.br/noticias/geral,com-menor-verbaem-12-anos--ciencia-perde-r-1-bi-e-bolsas-sao-congeladas, 1855374, acesso em 13 de abril.

\begin{tabular}{l|l|l|l|l|l|} 
(C) Rev. Inter. Educ. Sup. & Campinas, SP & v.2 & n.1 & p.138-151 & jan./abr. 2016
\end{tabular}

ISSN 2446-9424
} 
de educação superior (IES) e demais instituições científicas e tecnológicas (ICTs). (BRASIL, 2014, p.74,77-78)

No que se refere às ações que vem operacionalizando as diretrizes traçadas neste plano, destacamos a promulgação do Decreto n. 7642 de 13 de dezembro de 2011 que instituiu o Programa Ciências sem Fronteiras com o objetivo de "propiciar a formação e capacitação de pessoas com elevada qualificação em universidades, instituições de educação profissional e tecnológica, e centros de pesquisa estrangeiros de excelência", além de "atrair para o Brasil jovens talentos e pesquisadores estrangeiros de elevada qualificação, em áreas de conhecimento definidas como prioritárias". Na qual as ações empreendidas no âmbito desse Programa serão complementares às atividades de cooperação internacional e de concessão de bolsas no exterior com o envolvimento das agências CAPES e CNPq e do Ministério da Ciência, Tecnologia e Inovação.

Ciência sem Fronteiras é um programa que busca promover a consolidação, expansão e internacionalização da ciência e tecnologia, da inovação e da competitividade brasileira por meio do intercâmbio e da mobilidade internacional. A iniciativa é fruto de esforço conjunto dos Ministérios da Ciência, Tecnologia e Inovação (MCTI) e do Ministério da Educação (MEC), por meio de suas respectivas instituições de fomento - $\mathrm{CNPq}$ e Capes -, e Secretarias de Ensino Superior e de Ensino Tecnológico do MEC.[...] Além disso, busca atrair pesquisadores do exterior que queiram se fixar no Brasil ou estabelecer parcerias com os pesquisadores brasileiros nas áreas prioritárias definidas no Programa, bem como criar oportunidade para que pesquisadores de empresas recebam treinamento especializado no exterior.

Outra questão destacada no âmbito deste documento diz respeito ao financiamento da pós-graduação. Há indicação sobre a necessidade de flexibilização jurídica para o aprimoramento da afinação entre universidade, Estado e mercado.

Reforma do arcabouço legal, para que as agências de fomento federais e estaduais
tenham maior flexibilidade no uso dos recursos destinados a C,T\&I e que tenham a
concordância com os mecanismos adotados pelos órgãos de controle externo (TCU,
CGU, AGU e MPU e correspondentes órgãos na esfera estadual); Eliminação dos
entraves burocráticos que impedem as atividades de consultoria e assessoria de
pesquisadores do Regime Jurídico Único a empresas públicas e privadas, bem como
cerceiam a contratação pelo sistema público de consultores privadas e experts
nacionais e internacionais; redução das atividades burocráticas exigidas dos
pesquisadores na gestão dos recursos cedidos pelas agências (BRASIL, 2010,
p.303-304).

A partir da citação acima exposta, podemos concluir que estamos em pleno processo de mercantilização da educação superior Brasileira, sobretudo, com a publicação da Lei n. 13.243/2016, mas conhecido como Novo Código Nacional de Ciência, Tecnologia e Inovação. Em termos da Política nacional de internacionalização da pós-graduação, Sguissardi e Silva Júnior (2009) já indicavam em pesquisa anterior haver uma mudança na cultura político-institucional universitária, decorrentes da adesão do Brasil a um novo projeto mundializado de desenvolvimento econômico e produtivo. 
De acordo com os autores, as mudanças políticas e jurídicas dessa adesão, expressas com a Publicação do Plano Diretor de Reformas do Aparelho do Estado em 1995, começavam a ser deglutidas no âmbito acadêmico-institucional universitário, alterando a prática universitária dos professores das IFES pesquisadas e ainda na percepção de que o chamado 'polo irradiador' da reforma na instituição universidade pública seria a pósgraduação, considerada lócus privilegiado de produção do conhecimento, que se organiza, segundo os pesquisadores, por meio de três movimentos: o papel ocupado pela Capes na imposição de uma nova cultura acadêmico-institucional definida de produtivismo acadêmico; pelo papel atribuído ao CNPq de indutor à pesquisa aplicada e pelo mercado que se põe na universidade, possibilitando entre seus pesquisadores e o setor produtivo (SGUISSARDI; SILVA JÚNIOR, 2009).

Tal projeto de mercantilização exposto no atual PNPG (2011-2020) e retomado no PNE (2014-2024), tal como exposto na meta 14 "elevar gradualmente o número de matrículas na pós-graduação stricto sensu, de modo a atingir a titulação anual de sessenta mil mestres e vinte e cinco mil doutores", induz também a estratégias que passam a funcionalizar o Fundo público para a apropriação privada como demonstrado na meta 14.3 "expandir o financiamento estudantil por meio do Fies à pós-graduação stricto sensu".

\section{Elementos econômicos para o entendimento da internacionalização mercantilização da educação superior}

A economia que emerge depois da segunda guerra mundial produz historicamente demandas para a indústria, especialmente para as corporações no âmbito mundial, exigências estruturais que têm requerido uma diminuição de tempo entre a produção científica e sua aplicação em serviços, produtos e processos. A ciência, básica ou aplicada, voltada para o bem público tem aí uma pressão para mudança, sendo necessário um novo tipo de conhecimento que atenda a tais demandas, postas não mais por parâmetros exclusivamente científicos, mas também pela financeirização da economia. A economia converte-se, pois, no principal fator para a epistemologia da nova ciência acadêmica, que passa a ser regulamentada por várias leis e, especialmente pelo PNPG (2011-2020) e que ganha sua forma mais acabada no Novo Código Nacional de Ciência Tecnologia e Inovação de janeiro de 2016.

O conhecimento exigido pelas novas corporações tem entre suas redes de trabalho uma ou mais parcerias com universidades no mundo todo que se dão de diversas formas, estrategicamente por meio de transferência de tecnologia e pela venda de direitos autorais para as próprias universidades, como se pode observar no caso das pesquisas realizadas nas universidades estatais brasileiras. $\mathrm{O}$ conhecimento, na maioria das vezes, é transferido na forma de inovações sociais e tecnológicas e é o tipo de conhecimento que aqui denomino conhecimento matéria-prima (Raw Material Knowledge), termo que tem inspiração na

\begin{tabular}{l|l|l|l|l|l|l} 
(C) Rev. Inter. Educ. Sup. & Campinas, SP & v.2 & n.1 & p.138-151 & jan./abr. 2016 & ISSN 2446-9424 \\
\hline
\end{tabular}


leitura dos trabalhos de Gary Rhoades, Sheila Slaugther, Gustavo Fishman, Daniel Schugurenski e Phillip Altbach. Os formuladores das reformas são precisamente os pesquisadores profissionais produtores do Conhecimento Matéria Prima.

O conhecimento matéria-prima direciona-se para a economia mundializada por meio do capital financeiro pela sua própria exigência e é uma parte dos resultados da ciência em seu novo paradigma. Trata-se de conhecimento pronto para ser transformado em produtos de alta tecnologia, novos processos de produção e serviços e está relacionado à possibilidade de lucros imediatos no âmbito econômico. Aqui parece ser um bom lugar para comentarmos o que vem sendo definido como inovação tecnológica. Ao buscarmos a forma mais geral do que se poderia entender por inovação tecnológica, podemos encontrar que esta é um processo, ao mesmo tempo, de mudança, invenção e adaptação, que existe desde os primórdios da humanidade, e que teria como objetivo a melhoria da vida e do trabalho das pessoas e das empresas, agregando mais valor aos produtos no menor tempo possível. Certamente esta definição procede e seria impossível confrontá-la nesta formulação, porém é possível melhor especificá-la.

Até há bem pouco tempo, o grande problema do capital consistia em diminuir o gap entre a ciência e a tecnologia e, embora houvesse uma aproximação entre a universidade e a indústria, ocorria, porém, uma considerável demora na solução dos problemas. Os intelectuais das indústrias estavam distantes dos processos de pesquisa e os pesquisadores, ávidos na defesa da autonomia de sua pauta de pesquisa, permaneciam distantes do front industrial e econômico. Contudo, com a falência do regime monopolista de produção e a emergência da predominância financeira, este quadro se altera de forma radical. Ocorre que o ciclo de capital portador de juros faz dinheiro sem trabalho. Na equação marxista, temos D' > D. O proprietário do dinheiro investe, empresta e recebe os juros como forma de pagamento desta operação pela mera propriedade privada do dinheiro. Esta operação, além de econômica, é jurídica e impõe as taxas de juros e o tempo de pagamento do que é devido, desconsiderando o que irá ocorrer no processo de produção real de valor e exige ordenamento jurídico específico tal qual $\boldsymbol{O}$ Novo Código Legal de Ciência, Tecnologia e Inovação e o atual PNPG (2011-2020). É uma aposta com o menor risco e a maior rentabilidade.

Esta operação pode ser feita entre amigos, empresas, grupo de empresas, países e pelos principais agentes institucionais que atuam mundialmente, que são os fundos mutuais, os guias da gestão do sistema monetário mundial, aos quais se subordinam os fundos de pensão e os fundos dos grupos predominantemente industriais, o que caracteriza um regime de predominância financeira. Quais as consequências disso?

Juridicamente, o ciclo financeiro comprime não só o ciclo do capital em funções (as relações sociais de produção), como também as relações sociais em geral, altera a sociabilidade e subjetividade de todo cidadão e exige a produção de valor real em tempo recorde do trabalho vivo. Aí está o verdadeiro problema do capital e a necessidade de fazer desaparecer o gap entre ciência e tecnologia.

\begin{tabular}{l|l|l|l|l|l|l} 
() Rev. Inter. Educ. Sup. & Campinas, SP & v.2 & n.1 & p.138-151 & jan./abr. 2016 & ISSN 2446-9424
\end{tabular}




\section{Considerações finais}

Neste ponto, a universidade, a pesquisa, a formação docente para a educação básica nela produzidas cumprem o papel estratégico. Como? Redefinindo a ciência e o conhecimento e a formação de professores conforme a referida necessidade. Por esta via, a racionalidade econômico-financeira interpõe-se nas práticas cotidianas da vida universitária e das instituições escolares em geral. $\mathrm{O}$ que as pesquisas, o trabalho do pesquisador e do professor precisam apresentar é o conhecimento matéria-prima. São tais pesquisadores que irão pensar a formação dos professores do ensino médio, seu currículo, sua avaliação, metodologias e a cultura mercantil presente na universidade permeiam não somente as formulações, mas a prática no ensino médio no cotidiano da instituição escolar.

Interessa que ele dure um ciclo econômico e que novos conhecimentos dessa natureza sejam produzidos indefinidamente. Isso está na raiz das explicações da Teoria da Convergência das reformas educacionais, no financiamento das instituições escolares e universidades, na sua organização e gestão, na avaliação, na importância dos rankings, na necessidade da expansão e da internacionalização da educação superior, em nova divisão internacional do trabalho científico, no acesso e na produção de conhecimento produzido nessas instituições. As publicações se tornaram mercadoria nas mãos de seis editoras no mundo todo para as quais as universidades vendem os direitos autorais de produções de seus pesquisadores profissionais. Os pesquisadores recebem adicionais aos seus salários ao venderem seus direitos autorais por quantia razoável para as universidades em que trabalham.

Por outro lado, as publicações somente ocorrem em muitas áreas do conhecimento como a farmacêutica, as áreas tecnológicas e a matemática, somente depois que se tornaram patentes ou depois que uma equação matemática tornou-se um produto financeiro em Wall Street. Isso nos permite inferir ao menos, que os artigos ou qualquer tipo da maioria da publicação acadêmica constituem-se menos na socialização de conhecimento e se caracterizam mais como marketing do produto e do próprio pesquisador. A produção destes profissionais é o alicerce das reformas educacionais em todo mundo, particularmente no Brasil. É ilustrativo ver a trajetória dos intelectuais acadêmicos da comissão do Plano Nacional de Pós-Graduação (2011-2020). Suas conexões com os países centrais e com o Estado brasileiro são muito próximas. Busquem os intelectuais acadêmicos e descobrirão as relações entre a pesquisa das universidades em fase de internacionalização e as reformas educacionais.

Estas mudanças estruturais impõem ao pesquisador publicar em abundância e muitas vezes repetir o que já escreveu com a ajuda luxuosa da estética: as várias formas de plágio e autoplágio. As tecnologias de informações diminuem o tempo para a publicação e aumentam o tempo de aparição do texto e de seu autor que se identifica de forma incauta com a ciência financeirizada e, logo, precisamente administrada. 
A compressão espaço-temporal própria da sociedade atual e exigida pela economia mundial sob o predomínio do capital financeiro exige a compressão do tempo epistêmico e neurológico do pesquisador, produzindo, para ele, muito sofrimento. Esta situação aliena o ser humano trabalhador na universidade. Seu trabalho é fantasticamente voltado para a busca de resultados comercializáveis. A epifania de si mesmo traz-lhe de forma certeira o seu adoecimento e a atmosfera de uma vida estranha em que ele não sabe se é a sua própria sombra, sua imagem no espelho, sua foto digitalizada no Currículo Lattes, na página do ResearchGate ou na página do sítio Academia.edu. Suas dimensões humanas se estilhaçam e o fazem voltar-se contra si mesmo e identificar-se com a necessidade de "mais". Sem a satisfação humana contrária à meritocracia fake, a saída é a busca de momentos de paz artificial produzida pelo álcool, drogas ou, o pior, as drogas legais que não curam, mas produzem dependência para aumentar os lucros dos laboratórios farmacêuticos.

Para o entendimento da internacionalização da educação superior é estratégico a compreensão do papel dos intelectuais acadêmicos e suas relações com outros países através das epistemichal Communities (Comunidades Epistêmicas). A grande expansão de bolsas de pós-doutorados (SILVA JÚNIOR, 2016) e as diversas formas de pesquisadores pelo mundo todo produziu o saber único; o saber matéria prima, impôs a internacionalização da educação superior pelo papel estratégico que a instituição passou a assumir no âmbito do regime de predominância financeira ao passar a produzir, difundir o conhecimento cuja episteme tem sua base na economia financeira e formar docentes com a mesma racionalidade. Os Estados Unidos parecem continuar sendo o produtor da World Class University modelo que o Brasil tem seguido e que orienta em grande medida as reformas educacionais. Um dos mentores deste modelo escreve em seu livro The New American University:

A concepção de conhecimento para as empresas não é simples. Uma melhor aproximação dele consiste na correlação da estrutura ou organização da instituição, em que, o contexto e a produção de conhecimento impõem a consideração da reflexiva relação entre o conhecimento e o contexto institucional. (...) $\mathrm{O}$ conhecimento é situado como parte do produto de uma atividade, contexto, cultura, nas quais ele é desenvolvido e usado (CROW; DABARS, 2015, p. 177) (Tradução do original em inglês feita pelo autor).

É relevante notar uma vez mais a condição de país hegemônico, posição ocupada há décadas pelos Estados Unidos da América. Não menos relevante é a consideração das históricas relações entre Brasil e esse país.

A sistematização dos diferentes autores em diferentes lugares sociais e diferentes posições teóricas parecem mostrar o quanto existe de similaridade entre as mudanças na universidade estatal brasileira e na universidade dos EUA, embora as ocorridas no Brasil, a partir dos anos 1990, se deem muito tempo depois que nos EUA. A universidade americana é, sem dúvida, com pequenas brechas, uma instituição mundial. Contudo, é oportuno destacar que este fato se torna estrutural no século XXI como necessidade da economia mundializada. A mundialização da economia impôs a internacionalização da educação superior e do conhecimento matéria prima e produziu a convergência das reformas educacionais segunda à

\begin{tabular}{l|l|l|l|l|l|l} 
(C) Rev. Inter. Educ. Sup. & Campinas, SP & v.2 & n.1 & p.138-151 & jan./abr. 2016 & ISSN 2446-9424 \\
\hline
\end{tabular}


racionalidade financeira e exigiu a regulamentação da educação superior no Brasil como bem se buscou mostrar no iníco deste texto por meio do Novo Código Nacional de Ciência, Tecnologia e Inovação e, especialmente com o Plano Nacional de Pós-Graduação (20112020).

\section{Referências}

ALTBACH, P. The decline of the guru. Centres and peripheries in the academic profession: the special challenges of developing countries. 2003.

ALTBACH, P.G.; KNIGHT, J. The Internationalization of Higher Education: Motivations and Realities. Journal of Studies in International Education, Los Angeles: CA, Volume 11, Number 3/4, Fall/Winter, 2007.

ALTBACH, Philip. Patterns in Higher Education Development: Toward the Year 2000, in Emergent Issues in Education: Comparative Perspectives, 1992.

BRASIL. Ministério da Administração Federal e Reforma do Estado. Plano Diretor da Reforma do Aparelho do Estado. Brasília, DF, 1995.

BRASIL. Ministério da Educação. Coordenação de Aperfeiçoamento de Pessoal de Nível Superior. Plano Nacional de Pós-graduação-PNPG (2011-2020). Brasília, DF, 2010.

BRASIL. República Federativa do. Lei 13.005 de 25 de junho de 2014. Aprova o Plano Nacional de Educação - PNE e dá outras providências.

BRASIL. República Federativa do. Lei 13.243 de 11 de janeiro de 2016. Dispõe sobre os estímulos ao desenvolvimento científico à pesquisa, à capacitação científica e tecnológica e à inovação.

BRASIL/Capes. Plano Nacional de Pós-Graduação (2011-2020). Brasília, 2010.

Discurso da Presidenta da República, Dilma Rousseff, durante a cerimônia de sanção do marco legal da ciência, tecnologia e inovação e lançamento da chamada universal - Brasília/DF. Disponível em: <http// http://www2.planalto.gov.br/acompanhe-o-planalto/discursos/discursos-da-presidenta/discurso-dapresidenta-da-republica-dilma-rousseff-durante-a-cerimonia-de-sancao-do-marco-legal-da-cienciatecnologia-e-inovacao-e-lancamento-da-chamada-universal-brasilia-df > . Acesso em: 18 mar.2016.

KATO, Fabíola. A nova política de financiamento de pesquisas: reforma no Estado e no novo papel do CNPq. 2013.179f. Tese (Doutorado em Educação)-UFSCar, São Carlos.

OLIVEIRA, Francisco. Recuperando a Visão? (Prefácio). In: SGUISSARDI, Valdemar; SILVA JÚNIOR, João dos Reis. Trabalho intensificado nas federais - pós-graduação e produtivismo acadêmico. São Paulo: Xamã Editora, 2009.

PAULANI, Leda. Brasil Delivery. São Paulo: Boitempo Editorial, 2008. 
SGUISSARDI, Valdemar; SILVA JÚNIOR, João dos Reis. Trabalho intensificado nas federais: Pós-Graduação e produtivismo acadêmico. São Paulo: Xamã Editora, 2009.

SILVA JR, João dos Reis; KATO, Fabiola B. G.; FERREIRA, Luciana R. Universidade Pública Brasileira: mercantilização do conhecimento e certificação em massa. In: ARELARO, L.G; FRANCA, G. C.; MENDES, M.T (orgs). Às portas da universidade: alternativas de acesso ao ensino superior. São Paulo: Xamã, 2012, p.33-53.

SILVA JÚNIOR, J; KATO, F. B. G. PNPG (2011-2020): certificação em massa, internacionalização e mercantilização do conhecimento. In: SILVA JÚNIOR, João dos Reis; CATANI, Afrânio Mendes; CHAVES, Vera Jacob. Consequências da Mundialização da universidade pública brasileira: pós-graduação, trabalho docente, profissionalização e avaliação. São Paulo: Xamã, 2012.

SILVA JÚNIOR, João dos Reis. The New Brazilian University? A busca por resultados: para quem? Campinas: Editora Autores Associados. (No prelo para publicação em 2017) 